\title{
Visian implantable contact lens versus AcrySof Cachet phakic intraocular lenses: comparison of aberrmetric profiles
}

This article was published in the following Dove Press journal:

Clinical Ophthalmology

20 July 2013

Number of times this article has been viewed

\author{
Mohamed HM Hosny \\ Ahmad MM Shalaby \\ Department of Ophthalmology, \\ Faculty of Medicine, Cairo \\ University, Cairo, Egypt
}

Correspondence: Ahmad MM Shalaby Faculty of Medicine, Cairo University, 70 El-Manyal Street, El-Basha Square, Cairo II 45 I, Egypt

Tel +20223631008

Fax +20 233307073

Email ammshalaby@kasralainy.edu.eg
Purpose: To evaluate the in vivo aberrometric performance of two phakic intraocular lenses (PIOLs); the Visian implantable contact lens (ICL) and the AcrySof Cachet PIOL.

Methods: Thirty eight eyes from 29 patients with an age range of 23-32 years and more than $9 \mathrm{D}$ of myopia were divided into two groups; one group of 20 eyes received a Visian ICL model V4c, another group of 18 eyes received an AcrySof Cachet PIOL. Total higher order aberrations (HOAs) root mean square, total coma, and total spherical aberrations were recorded pre and 6 weeks postoperatively to evaluate and compare the aberrometric performance of the Visian ICL and the AcrySof Cachet PIOL implanted in highly myopic patients.

Results: Preoperatively, there were no significant differences in any studied parameters, except for preoperative spherical equivalent. Postoperatively, there were no statistically significant differences in the induction of HOAs between both PIOLs. The reduction in spherical aberrations was statistically significant in each group as well as in all study patients.

Conclusion: Both AcrySof Cachet PIOL and ICLs are effective phakic implants to correct high refractive errors. They both induce small amounts of negative spherical aberration that do not affect the total HOAs, yet reduce the positive ocular spherical aberration. This result is expected to improve the quality of vision in such patients.

Keywords: high myopia, higher order aberrations, refractive procedures, phakic implants

\section{Introduction}

Phakic intraocular lenses (PIOL) for the treatment of myopia, approved by the US Food and Drug Administration (FDA) in September 2004, ${ }^{1}$ work by diverging light rays so that the image of a viewed object is brought into focus onto the retina rather than in front of the retina. They can be placed either in the anterior chamber (in front of the iris) or in the posterior chamber (between the iris and the natural lens). ${ }^{2}$

PIOL surgery proved to be safer than excimer laser surgical correction for moderate to high myopia as it results in significantly less loss of best spectacle corrected visual acuity (BSCVA), better contrast sensitivity, and also scored higher on patient satisfaction/preference questionnaires. Moreover, they offer a broader range of treatable ametropia and faster visual recovery, ${ }^{2-4}$ in addition to being a reversible procedure. ${ }^{1}$

PIOL insertion requires intraocular surgery which carries the risk of endophthalmitis, surgically induced astigmatism, corneal endothelial cell loss, chronic uveitis, pupillary block glaucoma, pigment dispersion syndrome, and cataracts. In addition, the lens power calculation and surgical implantation of PIOLs require special techniques and the long term outcomes of several types of PIOLs are unknown. ${ }^{1}$ 
In our study, we evaluated the visual outcome of two FDA approved PIOLs for the correction of myopia, namely, the Visian Implantable Collamer Lens (ICL; STAAR Surgical, Monrovia, CA, USA), a posterior chamber PIOL, and the AcrySof Cachet PIOL (Alcon Laboratories Inc, Fort Worth, TX, USA), an anterior chamber PIOL, in terms of higher order aberration alteration.

\section{Patients and methods}

Our study was performed on 38 eyes from 29 patients with an age range of 23-32 years. They were divided into two groups; one group of 20 eyes received Visian ICL model V4c, another group of 18 eyes received an AcrySof Cachet PIOL. The study was performed with informed consent and following all the guidelines for experimental investigations required by the Ethics Committee of Faculty of Medicine, Cairo University.

The ICL is currently the most widely used posterior chamber PIOL. It incorporates material with increased biocompatibility known as Collamer $(0.2 \%$ collagen and $60 \%$ hydroxylethyl methacrylate copolymer). This material attracts the deposition of a monolayer of fibronectin on the IOL surface that inhibits aqueous protein binding and makes the IOL invisible to the immune system. The ICL's design and materials were refined through a series of prototypes in different clinical trials. ${ }^{5}$ The current model, the Visian ICL V4, is a rectangular single-piece IOL, 7.5 to $8.0 \mathrm{~mm}$ wide, available in four overall lengths: 11.5 to $13.0 \mathrm{~mm}$ in $0.5 \mathrm{~mm}$ steps for myopic correction and 11.0 to $12.5 \mathrm{~mm}$ in $0.5 \mathrm{~mm}$ steps for hyperopic correction. The optic diameter ranges from 4.65 to $5.5 \mathrm{~mm}$ in myopic ICLs, depending on the dioptric power. It is always $5.5 \mathrm{~mm}$ in hyperopic ICLs. The available power ranges from -3.0 to -23.0 diopter (D) for myopic IOLs, from +3.0 to +22.0 D for hyperopic ICLs, and with an added positive cylinder of +1.0 to $+6.0 \mathrm{D}$ for toric ICLs correcting myopia. ${ }^{6,7}$ A model has been recently introduced with a central hole to alleviate the need for a peripheral iridectomy. ${ }^{8,9}$

The AcrySof Cachet is a single-piece, foldable, soft acrylic PIOL with a chemically bonded ultraviolet lightfiltering chromophore (acrylate-methacrylate copolymer) and is intended for implantation in the anterior chamber angle. ${ }^{10}$ All models have a $6.0 \mathrm{~mm}$ meniscus optic and are available in half diopter increments from -6.00 to $-16.50 \mathrm{D}$; overall lengths are $12.5 \mathrm{~mm}, 13.0 \mathrm{~mm}, 13.5 \mathrm{~mm}$, and $14.0 \mathrm{~mm} .{ }^{11}$ The haptics are designed to allow compression within the angle for IOL stability without creating excessive force that could cause angle tissue damage or pupil ovalization. The vault of the IOL is designed to provide optimal central clearance distance between the IOL and the cornea and the natural crystalline lens. These characteristics are intended to achieve predictable implantation, stable vaulting, and low compression forces on the angle while minimizing corneal endothelial cell loss, pupil ovalization, and cataract formation. ${ }^{10}$

All eyes had the same preoperative workup including scheimpflug imaging (Pentacam ${ }^{\circledR}$, OCULUS Optikgerate GmbH, Wetzlar, Germany) to analyze corneal higher order aberrations (HOAs) as well as aberrometry (VisX Wavescan, Abbott Medical Optics, Santa Ana, CA, USA) for total wavefront analysis. The total HOA root mean square (RMS), total coma, and total spherical aberrations were recorded pre and 6 weeks postoperatively.

The ICL was implanted in 20 eyes, with a mean preoperative spherical equivalent of $-12.9 \mathrm{D} \pm 2.38(-20 \mathrm{D}$ to $-9 \mathrm{D})$ and a mean cylinder of $-1.15 \mathrm{D} \pm 0.71(-3 \mathrm{D}$ to $-0.5 \mathrm{D})$. The size was calculated based on the white to white (W-T$\mathrm{W})$ diameter after adding $0.5 \mathrm{~mm}$ to the measurement of the pentacam. On the day of surgery, the patients were given dilating and cycloplegic agents. Under the appropriate anesthetic technique, a model V4 ICL was inserted through a $3 \mathrm{~mm}$ clear corneal incision with the use of an injector cartridge (STAAR Surgical) after placement of an ophthalmic viscosurgical device (OVD) into the anterior chamber. The ICL was placed in the posterior chamber, the remaining OVD was completely washed out of the anterior chamber with balanced salt solution, and a miotic agent was instilled. A peripheral iridectomy was done using the vitreous cutter.

The AcrySof Cachet IOL was implanted in 18 eyes, with a mean preoperative spherical equivalent of $-14.94 \mathrm{D} \pm 3.096(-22 \mathrm{D}$ to $-11 \mathrm{D})$ and a mean cylinder of $-1.75 \mathrm{D} \pm 1.16(-4 \mathrm{D}$ to $0 \mathrm{D})$. The size was calculated based on the W-T-W measured by the IOLMaster (Carl Zeiss, Jena, Germany). Before surgery, the pupil was constricted (pilocarpine 2\%) to prevent potential contact with the crystalline lens. Under the appropriate anesthetic technique, pupillary constriction was secured by intracameral injection of acetylcholine chloride intraocular solution $1 \%$. The IOL was inserted into the anterior chamber through a $2.6 \mathrm{~mm}$ clear corneal incision with the use of a Monarch III IOL delivery system (Alcon Laboratories Inc) after placement of an OVD tangentially into the angle, away from the pupil. The correct IOL position was verified and the OVD was removed by passive irrigation. Iridectomy or iridotomy at the time of surgery was not considered necessary and therefore was not performed. 


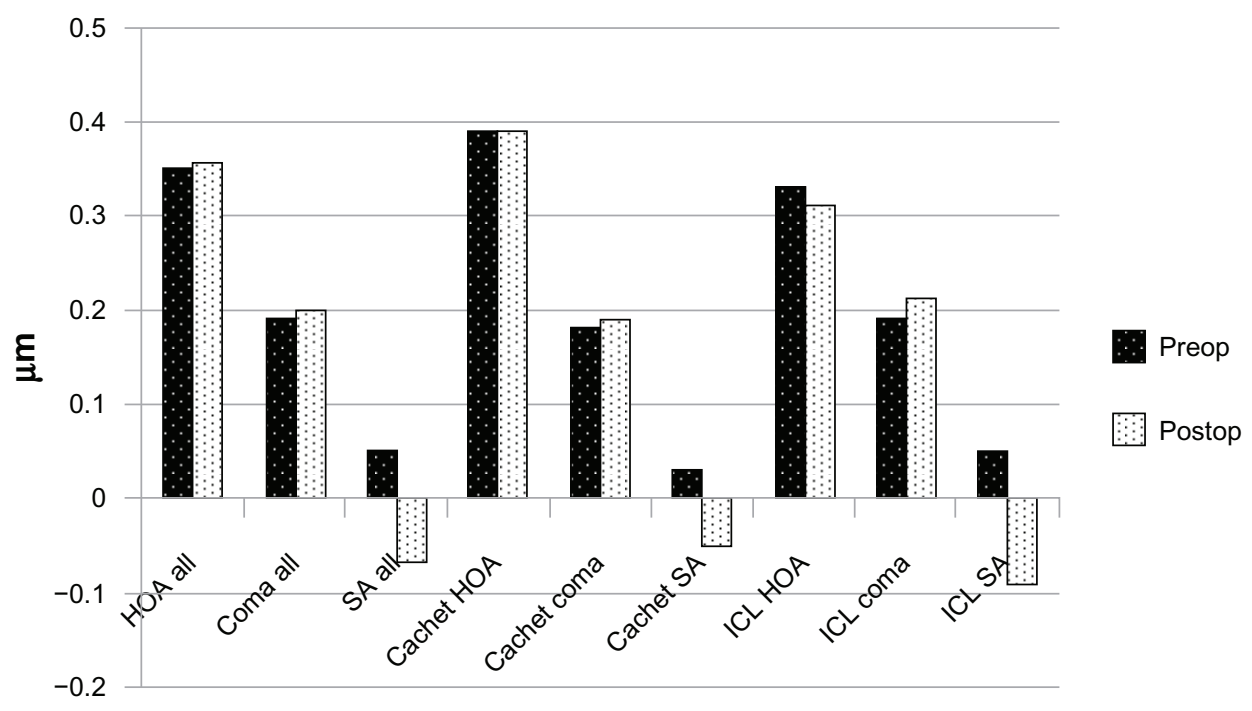

Figure I HOA analysis.

Abbreviations: HOA, higher order aberrations; ICL, implantable contact lens; Postop, postoperative; Preop, preoperative; SA, spherical aberrations.

Postoperative treatment for both groups included steroidal and antibiotic eye drops, administered four times daily for 2 weeks, and the dose was steadily reduced thereafter.

Bioptics, ${ }^{12-14}$ in the form of a preoperative lasik flap creation 1-week before the phakic lens implantation, then a flap lift and wavefront-guided lasik 6 weeks later was performed on six patients in this study, whose refractive error was not within the range of correction offered by the phakic IOLs. One patient in the ICL group had high spherical error $(-20 \mathrm{D})$, one patient in the Cachet group had high cylindrical error (4 D), and another four in the Cachet group had both high spherical ( $-22 \mathrm{D}$ to $-18 \mathrm{D})$ and cylindrical errors (3 D to 3.5 D). In these patients, the preoperative measurements were performed on the day of the phakic implant procedure, while the postoperative measurements were performed before the final laser-assisted in situ keratomileusis, to isolate the effect of the phakic implant on the HOAs. Also, three patients in the ICL group received toric implants.

Statistics were performed using the Microsoft Office Excel 2010 (Microsoft Corporation, Redmond, WA, USA). $P$ values less than 0.05 were considered an indication of a significant difference between the two groups.

\section{Results}

Our study was performed on 38 eyes from 29 patients with an age range of 23-32 years, divided into two groups. The first group of 20 eyes received the Visian ICL model V4c (17 eyes received the spherical model and three eyes received the toric model). The second group of 18 eyes received an AcrySof Cachet PIOL. Significant change was evident in spherical equivalent refraction and spherical aberrations
Table I Patient data in the study population

\begin{tabular}{|c|c|c|c|}
\hline & Preoperative & Postoperative & $P$-value \\
\hline \multicolumn{4}{|l|}{ ICL group $(n=20)$} \\
\hline Spherical equivalent $D$ & $-12.9 \pm 2.38$ & $-1.015 \pm 1.01$ & $<0.001$ \\
\hline$($ mean $\pm \mathrm{SD})$ & $(-20 \mathrm{D}$ to $-9 \mathrm{D})$ & $(-5 \mathrm{D} \text { to } 0 \mathrm{D})^{\S}$ & \\
\hline Cylinder D & $-1.15 \pm 0.71$ & $-0.7625 \pm 0.39$ & 0.039 \\
\hline$($ mean $\pm S D)$ & $(-3 \mathrm{D}$ to $-0.5 \mathrm{D})$ & $(-1.25 \mathrm{D} \text { to } 0 \mathrm{D})^{*}$ & \\
\hline Total HOA RMS $\mu$ & $0.327 \pm 0.08$ & $0.3125 \pm 0.068$ & 0.54 \\
\hline$($ mean $\pm S D)$ & $(0.17$ to 0.4$)$ & (0.2 to 0.36$)$ & \\
\hline Coma aberration & $0.194 \pm 0.06$ & $0.205 \pm 0.059$ & 0.57 \\
\hline $\mathrm{RMS} \mu($ mean $\pm \mathrm{SD})$ & (0.II to $0.3 \mathrm{I})$ & $(0.15$ to 0.3$)$ & \\
\hline Spherical aberration & $0.052 \pm 0.039$ & $-0.0925 \pm 0.056$ & $<0.001$ \\
\hline $\mathrm{RMS} \mu($ mean $\pm \mathrm{SD})$ & (0 to 0.1$)$ & $(-0.15$ to -0 & \\
\hline \multicolumn{4}{|l|}{ Cachet group $(n=18)$} \\
\hline Spherical equivalent D & $-14.94 \pm 3.096$ & $-1.86 \pm 1.87$ & $<0.001$ \\
\hline$($ mean \pm SD) & $(-22 \mathrm{D}$ to $-11 \mathrm{D})$ & $(-7 \mathrm{D} \text { to }-0.25 \mathrm{D})^{*}$ & \\
\hline Cylir & $-1.75 \pm 1.16$ & $-1.75 \pm 1.16$ & I \\
\hline$($ mean $\pm S D)$ & $(-4 \mathrm{D}$ to $0 \mathrm{D})$ & $(-4 \mathrm{D} \text { to } 0 \mathrm{D})^{*}$ & \\
\hline Total HOA RMS $\mu$ & $0.394 \pm 0.16$ & $0.393 \pm 0.15$ & 0.992 \\
\hline$($ mean $\pm S D)$ & $(0.11$ to 0.65$)$ & $(0.12$ to 0.65$)$ & \\
\hline aberration & $0.186 \pm 0.1$ & $0.192 \pm 0.14$ & 0.895 \\
\hline $\mathrm{RMS} \mu($ mean $\pm \mathrm{SD})$ & (0.05 to 0.56$)$ & (0.05 to 0.56$)$ & \\
\hline Spherical aberration & $0.037 \pm 0.084$ & $-0.054 \pm 0.091$ & 0.0039 \\
\hline $\mathrm{RMS} \mu($ mean $\pm \mathrm{SD})$ & $(-0.1$ to 0.28$)$ & $(-0.25$ to 0.13$)$ & \\
\hline \multicolumn{4}{|l|}{ All $(n=38)$} \\
\hline Spherical equivalent D & $-13.87 \pm 2.896$ & $-1.42 \pm 1.52$ & $<0.001$ \\
\hline (mean $\pm \mathrm{SD})$ & $(-22 \mathrm{D}$ to $-9 \mathrm{D})$ & $(-7 \mathrm{D}$ to $0 \mathrm{D})$ & \\
\hline Cylinder D & $-1.43 \pm 0.98$ & $-1.23 \pm 0.97$ & 0.366 \\
\hline$($ mean $\pm S D)$ & $(-4 \mathrm{D}$ to $0 \mathrm{D})$ & $(-4 D$ to $0 D)$ & \\
\hline Total HOA RMS $\mu$ & $0.359 \pm 0.13$ & $0.35 \pm 0.122$ & 0.786 \\
\hline$($ mean $\pm S D)$ & (0.II to 0.65$)$ & $(0.12$ to 0.65$)$ & \\
\hline Coma aberration & $0.19 \pm 0.1$ & $0.199 \pm 0.104$ & 0.715 \\
\hline $\mathrm{RMS} \mu($ mean $\pm \mathrm{SD})$ & (0.05 to 0.56$)$ & (0.05 to 0.56$)$ & \\
\hline Spherical aberration & $0.045 \pm 0.064$ & $-0.074 \pm 0.076$ & $<0.001$ \\
\hline $\mathrm{RMS} \mu($ mean $\pm \mathrm{SD})$ & $(-0.1$ to 0.28$)$ & $(-0.25$ to 0.13$)$ & \\
\hline
\end{tabular}

Notes: $P<0.05$ is considered statistically significant; ${ }^{5}$ one bioptics procedure; *three toric ICLs implanted; ${ }^{*}$ five bioptics procedures.

Abbreviations: D, diopter; HOA, higher order aberrations; ICL, implantable contact lens; RMS, root mean square; SD, standard deviation. 
RMS (which changed from positive to negative) in each group separately and in the study population as a whole (Figure 1). In the ICL group only, the cylindrical error also significantly improved. The pre and postoperative patient data are represented in Table 1.

Comparing the two groups preoperatively, the difference was not significant in any studied parameters, except for the preoperative spherical equivalent. This similarity encouraged us to compare the HOA between the two groups postoperatively and again, both IOLs performed similarly regarding their effect on HOAs. There was no significant difference between the two groups in terms of postoperative RMS of the total HOAs (Figure 2), coma (Figure 3), or spherical (Figure 4) aberrations. Only the effective blur (Figure 5) was significantly lower in the ICL group patients compared to the Cachet group (Table 2).

Again, with regards to the induction of HOAs (Figure 6), both IOLs behaved similarly. The induction of total HOAs, coma-like aberrations, and sphericallike aberrations were $-0.015 \pm 0.026 \mu \mathrm{m}(-0.05$ to

A 0.7

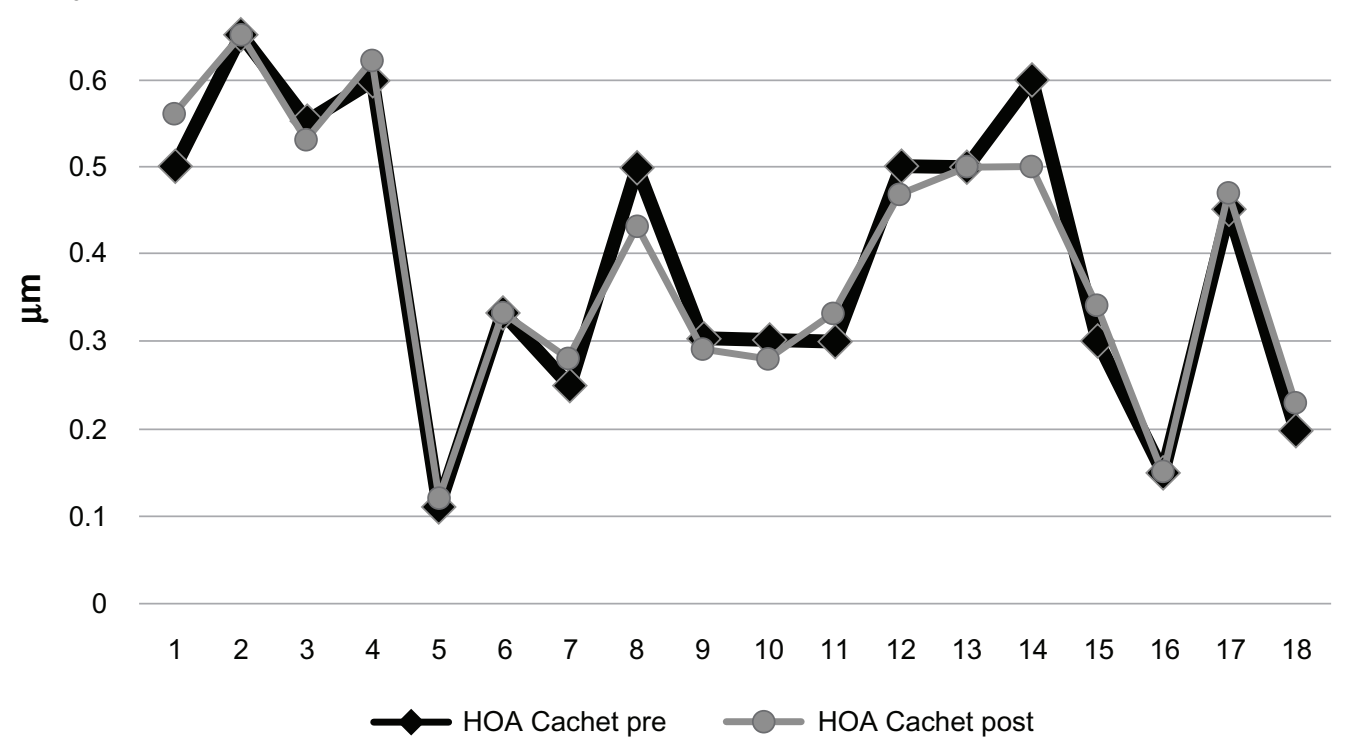

B $0.45 \longrightarrow$

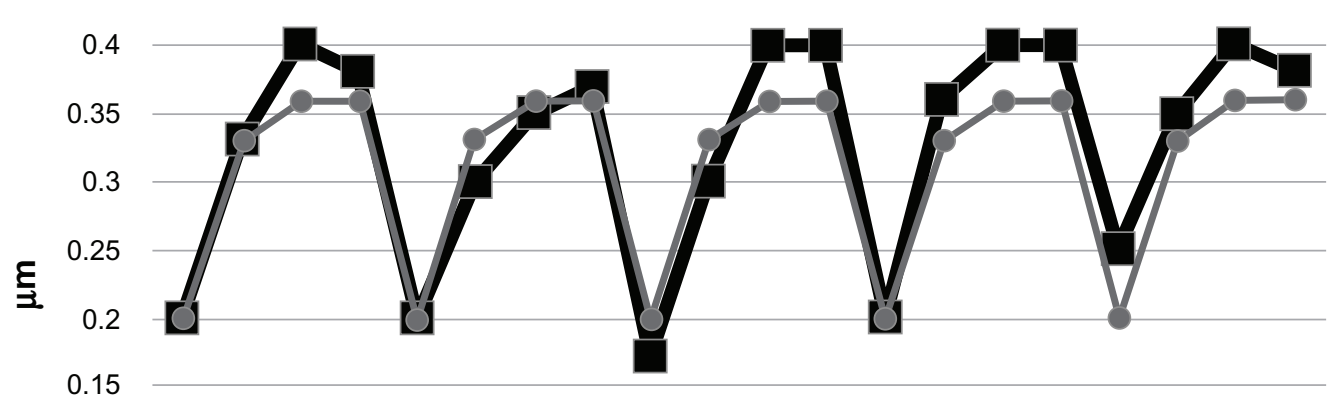

0.1

0.05

0

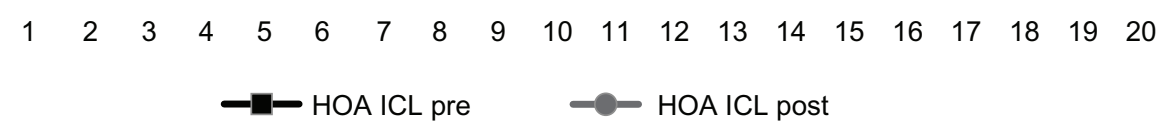

Figure 2 Total HOAs in both groups.

Notes: (A) Cachet. (B) Visian ICL.

Abbreviations: HOA, higher order aberrations; ICL, implantable contact lens; post, postoperative; pre, preoperative. 

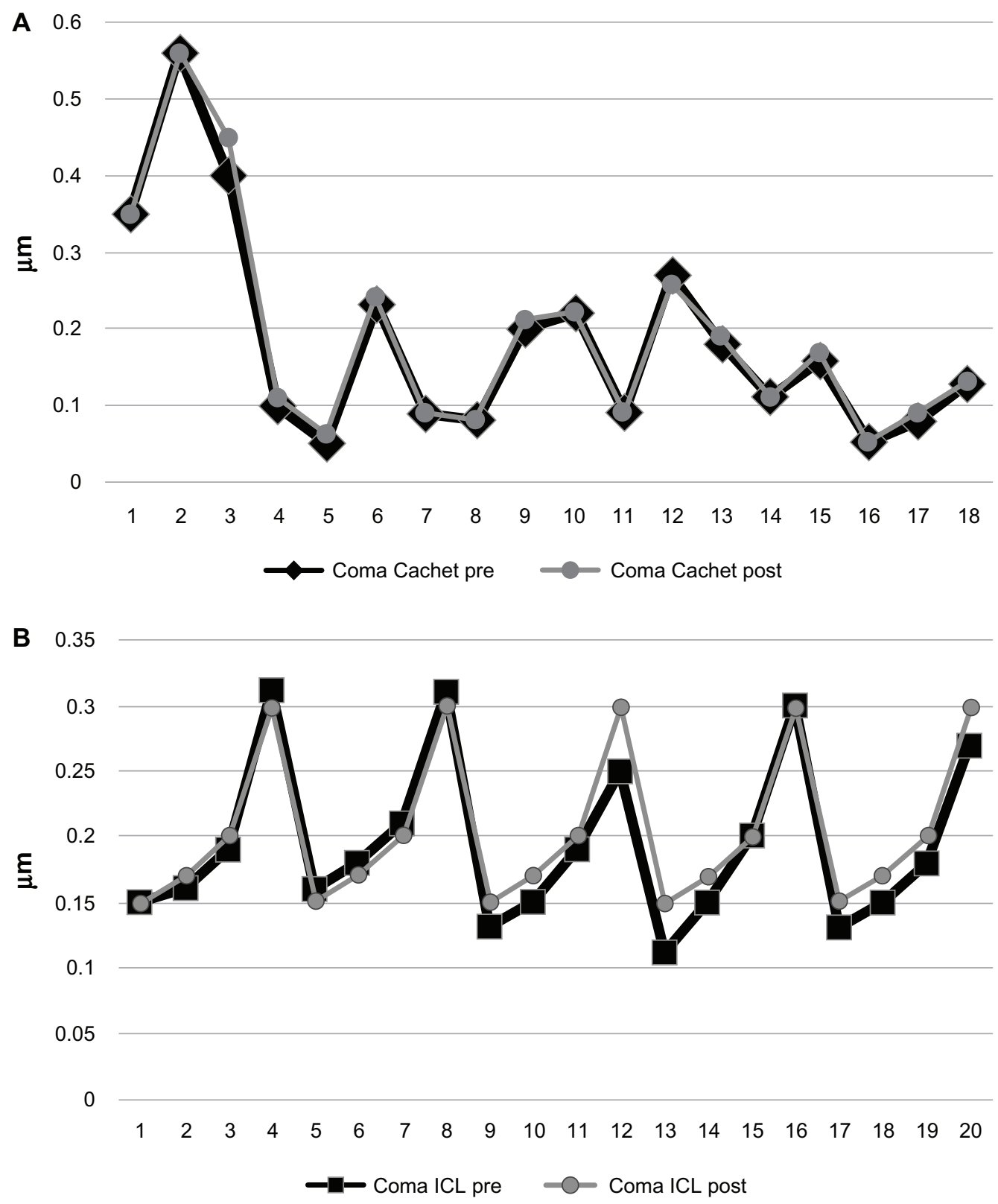

Figure 3 Coma aberrations in both groups.

Notes: (A) Cachet. (B) Visian ICL.

Abbreviations: ICL, implantable contact lens; post, postoperative; pre, preoperative.

$0.03 \mu \mathrm{m}), 0.011 \pm 0.017 \mu \mathrm{m}(-0.01$ to $0.05 \mu \mathrm{m})$, and $-0.14 \pm 0.07 \mu \mathrm{m}(-0.25$ to $0.02 \mu \mathrm{m})$, respectively for the ICL group. The inductions of total HOAs, coma-like aberrations, and spherical-like aberrations were $-0.0001 \pm 0.039$ $\mu \mathrm{m}(-0.1$ to $0.06 \mu \mathrm{m}), 0.006 \pm 0.012 \mu \mathrm{m}$ ( -0.01 to 0.05 $\mu \mathrm{m})$, and $-0.09 \pm 0.12 \mu \mathrm{m}(-0.53$ to $0 \mu \mathrm{m})$, respectively, for the Cachet group. The difference was not statistically significant $(P=0.21,0.32$, and 0.12 for the induction of total HOAs, coma-like aberrations, and spherical-like aberrations, respectively).

\section{Discussion}

The goal of refractive surgery is to safely and predictably create a stable and desired refractive state without causing new optical problems. In order to correct myopia the refractive power of the eye must be decreased, either by corneal refractive surgery, flattening the curvature of the anterior corneal surface, or by lenticular refractive surgery, through insertion of a PIOL of appropriate power ${ }^{2}$ or by refractive lens exchange. ${ }^{15,16}$ Although corneal surgery is the most common method used to treat low to moderate levels of myopia, it may 
A $\quad 0.4$

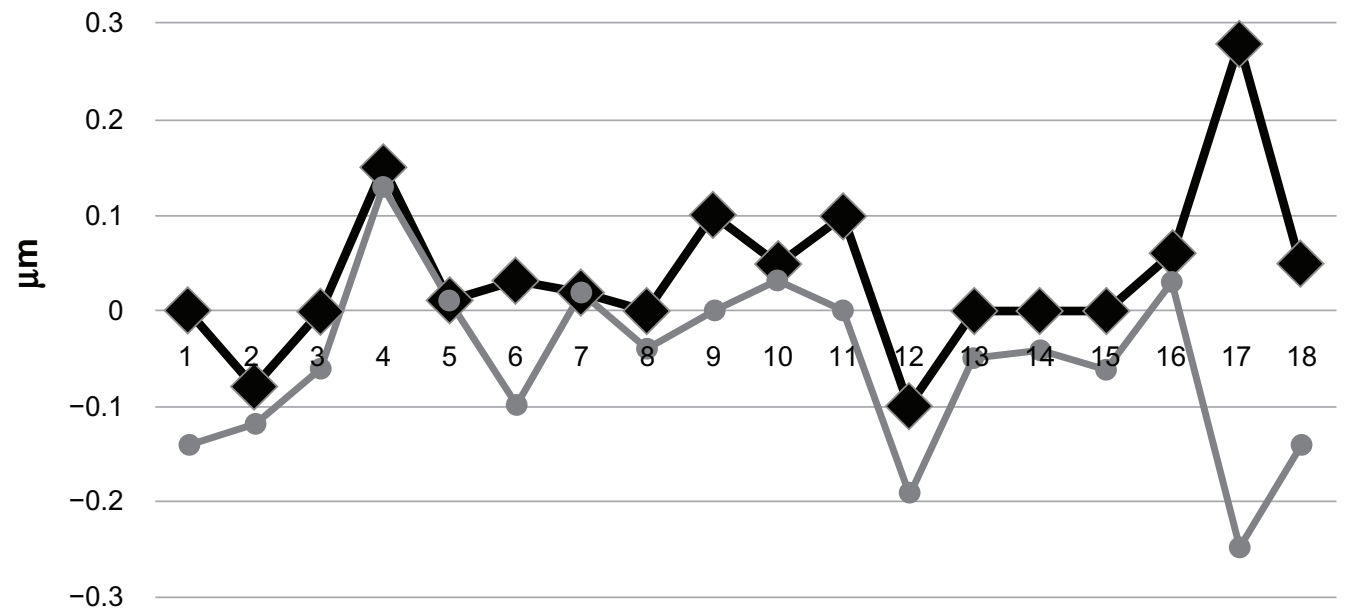

$-0.3$

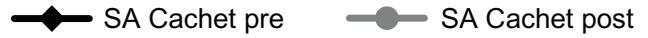

B $\quad 0.15$

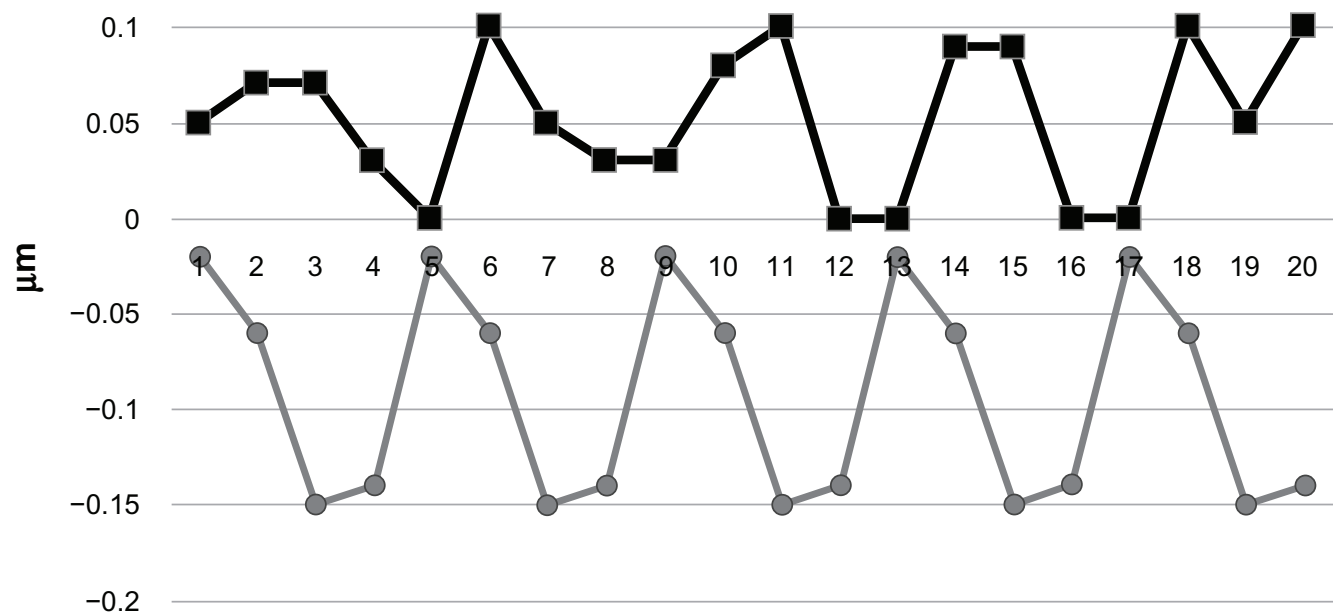

- - SA ICL pre $\quad-$ SA ICL post

Figure 4 Spherical aberrations in both groups.

Notes: (A) Cachet. (B) Visian ICL.

Abbreviations: ICL, implantable contact lens; post, postoperative; pre, preoperative; SA, spherical aberrations.

not be the best option for high myopia due to various factors. It has also been shown that PIOLs provide better visual quality, faster visual recovery, excellent refractive accuracy and stability, improved visual acuity, preservation of accommodation, and reversibility when compared to corneal surgery. ${ }^{7,17}$

Over the past few years, the concern with the ocular aberrations, especially HOAs, in any refractive surgical procedure is increasing. ${ }^{11,18,19}$ In our study, our main concern was with the HOAs after implantation of two PIOLs, namely the posterior chamber Visian ICL PIOL and the anterior chamber AcrySof Cachet.
The most prevalent HOAs in studies of the normal population were from 3rd order (horizontal trefoil, vertical coma, horizontal coma, and oblique trefoil) and 4th order (horizontal and oblique tetrafoil, horizontal and vertical secondary astigmatism, and spherical) Zernike terms. The contribution of each HOA progressively decreased with order except the 4 th order spherical aberration. Despite the variability between studies addressing this subject, the anterior corneal 4th order spherical aberration had positive values. ${ }^{20}$ They represent a major component of $\mathrm{HOAs}^{21}$ and exhibit a strong influence on image quality. ${ }^{22}$ Higher contrast 


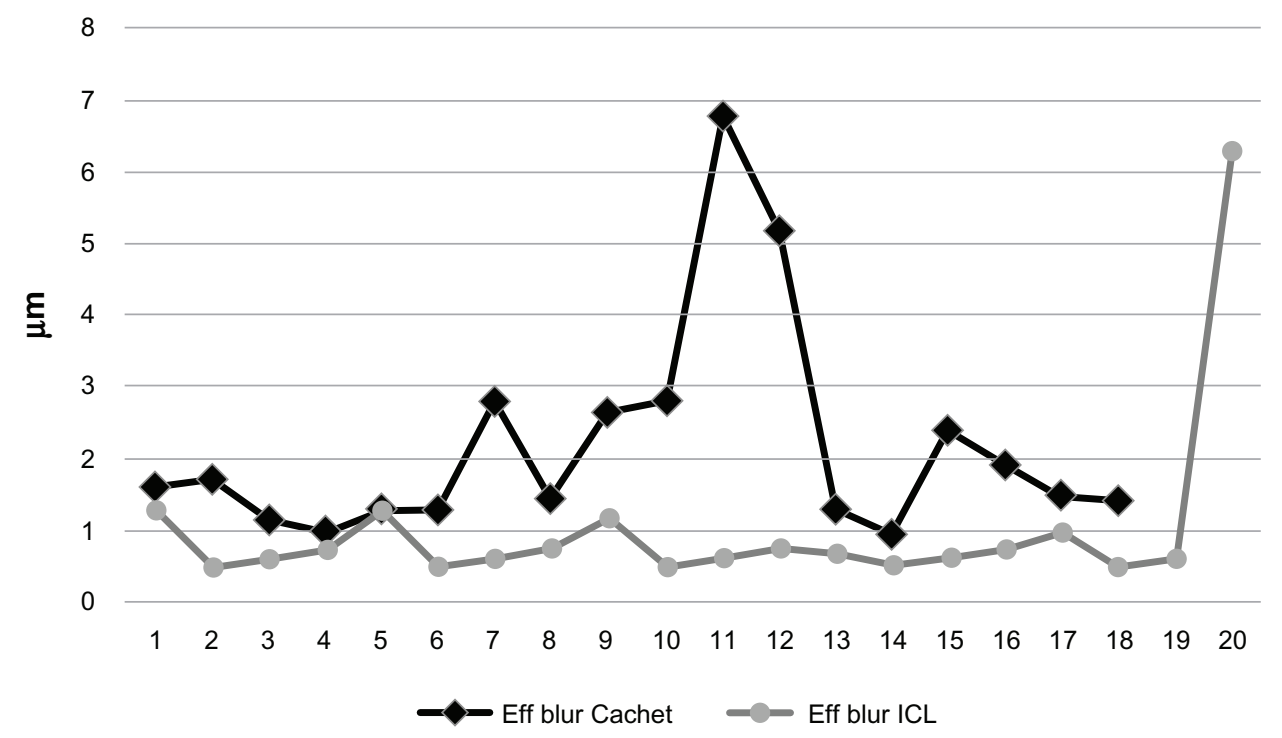

Figure 5 Postoperative effective blur in both groups.

Abbreviations: Eff, effective; ICL, implantable contact lens.

sensitivity values have been found in eyes with less spherical aberration. ${ }^{23,24}$ Phakic myopic implants, being minus lenses, are supposed to induce negative spherical aberrations. This should negate most of the corneal positive spherical aberrations or even exceed it. ${ }^{11,18,25}$

Table 2 Comparison of the outcome between the two groups

\begin{tabular}{|c|c|c|c|}
\hline & $\begin{array}{l}\text { ICL group } \\
(n=20)\end{array}$ & $\begin{array}{l}\text { Cachet group } \\
(n=18)\end{array}$ & $P$-value \\
\hline \multicolumn{4}{|l|}{ Preoperative } \\
\hline Spherical equivalent D & $-12.9 \pm 2.38$ & $-14.94 \pm 3.096$ & 0.03 \\
\hline$($ mean $\pm S D)$ & $(-20 \mathrm{D}$ to $-9 \mathrm{D})$ & $(-22 \mathrm{D}$ to $-1 \mathrm{I} \mathrm{D})$ & \\
\hline Cylinder D & $-1.15 \pm 0.7 \mid$ & $-1.75 \pm 1.16$ & 0.068 \\
\hline$($ mean $\pm S D)$ & $(-3 \mathrm{D}$ to $-0.5 \mathrm{D})$ & $(-4 \mathrm{D}$ to $0 \mathrm{D})$ & \\
\hline Total HOA RMS $\mu$ & $0.327 \pm 0.08$ & $0.394 \pm 0.16$ & 0.13 \\
\hline$($ mean $\pm S D)$ & $(0.17$ to 0.4$)$ & $(0.05$ to 0.56$)$ & \\
\hline Coma aberration & $0.194 \pm 0.06$ & $0.186 \pm 0.137$ & 0.82 \\
\hline $\mathrm{RMS} \mu($ mean $\pm \mathrm{SD})$ & (0.II to $0.3 \mathrm{I})$ & (0.05 to 0.56$)$ & \\
\hline Spherical aberration & $0.052 \pm 0.039$ & $0.037 \pm 0.084$ & 0.5 \\
\hline RMS $\mu($ mean $\pm S D)$ & (0 to 0.1$)$ & $(-0.1$ to 0.28$)$ & \\
\hline \multicolumn{4}{|l|}{ Postoperative } \\
\hline Spherical equivalent D & $-1.015 \pm 1.01$ & $-1.86 \pm 1.87$ & 0.099 \\
\hline$($ mean $\pm \mathrm{SD})$ & $(-5 \mathrm{D} \text { to } 0 \mathrm{D})^{\S}$ & $(-7 \mathrm{D} \text { to }-0.25 \mathrm{D})^{*}$ & \\
\hline Cylinder D & $-0.7625 \pm 0.39$ & $-1.75 \pm 1.16$ & 0.0025 \\
\hline$($ mean $\pm S D)$ & $(-1.25 \mathrm{D} \text { to } 0 \mathrm{D})^{*}$ & $(-4 \mathrm{D} \text { to } 0 \mathrm{D})^{*}$ & \\
\hline Total HOA RMS $\mu$ & $0.3125 \pm 0.068$ & $0.393 \pm 0.15$ & 0.053 \\
\hline$($ mean $\pm S D)$ & $(0.2$ to 0.36$)$ & $(0.12$ to 0.65$)$ & \\
\hline Coma aberration & $0.205 \pm 0.059$ & $0.192 \pm 0.14$ & 0.72 \\
\hline RMS $\mu($ mean $\pm S D)$ & $(0.15$ to 0.3$)$ & (0.05 to 0.56$)$ & \\
\hline Spherical aberration & $-0.0925 \pm 0.056$ & $-0.054 \pm 0.091$ & 0.13 \\
\hline $\mathrm{RMS} \mu($ mean $\pm \mathrm{SD})$ & $(-0.15$ to -0.02$)$ & $(-0.25$ to 0.13$)$ & \\
\hline Effective blur $\mu$ & $1.015 \pm 1.27$ & $2.17 \pm 1.53$ & 0.017 \\
\hline$($ mean $\pm \mathrm{SD})$ & (0.5 to 6.3$)$ & (0.96 to 6.77$)$ & \\
\hline
\end{tabular}

Notes: $P<0.05$ is considered statistically significant; ${ }^{\circ}$ one bioptics procedure; *three toric ICLs implanted; $*$ five bioptics procedures.

Abbreviations: D, diopter; HOA, higher order aberrations; ICL, implantable contact lens; RMS, root mean square; SD, standard deviation.
In this study, we evaluated the total and not internal HOA for two reasons; first to study the end effect of the lens after interacting with both internal and corneal HOAs especially spherical aberrations and second to include the changes that can occur in the corneal HOA due to the surgery itself, especially the incision ${ }^{11,18,19}$ even though its small size should not have much impact on the outcome of the procedure. ${ }^{26}$

In our patient sample, the postoperative change in spherical aberrations RMS (from positive to negative) in each group separately and in the total study population was statistically significant due to the negative spherical aberrations induced by the PIOLs, while the total and coma aberration RMS change was not statistically significant (Figure 1 and Table 1). This was similar to the findings reported by Toso and Morselli ${ }^{11}$ when studying the aberrometric performance of the Cachet PIOL as well as by Shin et $\mathrm{a}^{19}$ and Kamiya et a ${ }^{27}$ when evaluating the Visian ICL. Even in other studies that considered the patient satisfaction in terms of visual acuity, quality of vision or halos and glare, PIOL implantation proved to be better when the Cachet, ${ }^{10,28}$ ICL $^{17,29}$ or both ${ }^{26,30}$ were evaluated.

Regarding the other parameters evaluated, there was a statistically significant improvement in postoperative spherical equivalent refraction in each group separately as well as in the total study population. This is expected as the PIOL corrected the pre-existing refractive error. Safety and efficacy of both PIOLs have been previously studied. ${ }^{10,17,26,28-30}$ The cylindrical error did not improve in the Cachet group as well as in the total study population as the implanted PIOLs didn't affect the pre-existing astigmatic error. This was not 

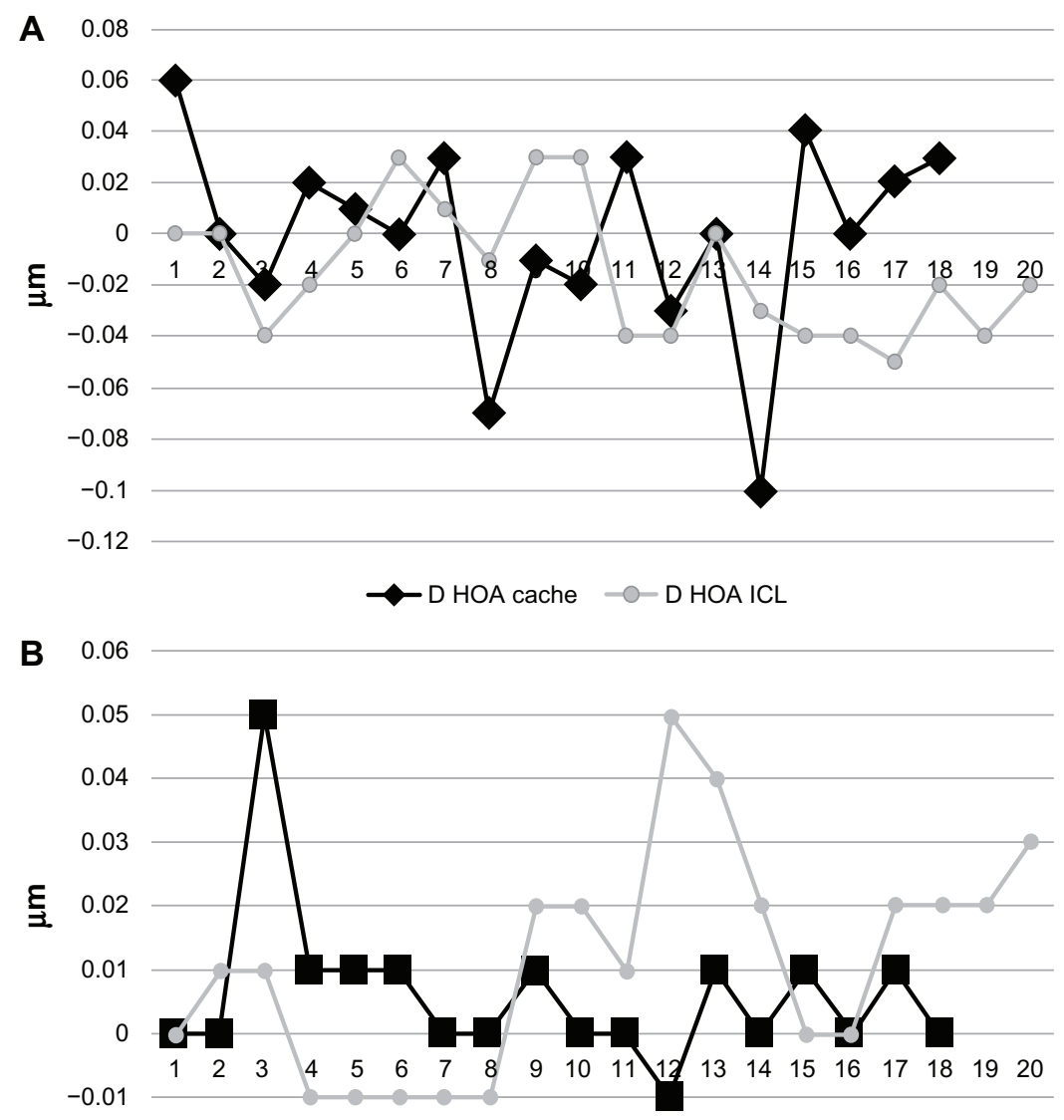

$-0.02$

D Coma Cache $-0-$ D Coma ICL

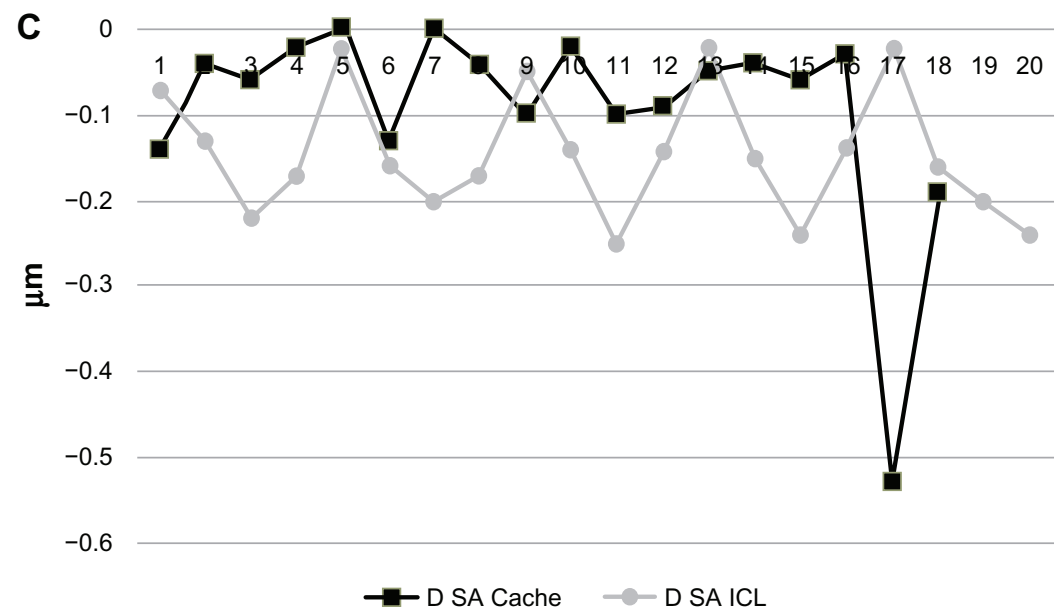

Figure 6 Induction of ocular aberrations in both groups.

Notes: (A) Total HOAs. (B) Coma aberrations. (C) Spherical aberrations.

Abbreviations: D, delta; HOA, higher order aberrations; ICL, implantable contact lens; SA, spherical aberrations.

the case among the ICL group in whom the three toric ICLs were implanted, which significantly improved the pre-existing astigmatic error (Table 1). Toric IOLs were not used in other patients of the ICL group or those of the Cachet group due to availability issues.
When both PIOLs were compared (Table 2), no statistically significant difference existed between all preoperative parameters except for the spherical equivalent. Postoperatively, again both PIOLs showed similar behavior, with no statistically significant difference between all 
parameters including the induction of aberrations, except for the postoperative cylinder and the effective blur which were significantly better in the ICL group. The reduction in the cylindrical refraction in the ICL groups could be explained by the use of the three toric implants in this group, which resulted in a significantly lower postoperative cylindrical error compared to the Cachet group in whom no toric implants were used. The reduction in the postoperative cylindrical error in the ICL group, together with the ICL being implanted behind the iris (the shutter of the ocular optical system) could explain the effective blur being significantly lower in the ICL group compared to the Cachet PIOL which is implanted in the anterior chamber, in front of the iris with an unchanged astigmatic error.

Though each of the PIOLs studied in our work was evaluated separately in multiple previous studies, ${ }^{10,11,17,19,26-30}$ to our knowledge, this is the first study to compare both PIOLs with respect to the induction of total HOAs, coma, and spherical aberrations. We found a similar behavior between both PIOLs in almost all parameters. Both PIOLs had no significant effect on the induction of total HOAs and coma aberrations, but significantly reduced the spherical aberrations in a similar manner. Evaluating both PIOLs on a larger population, with a longer follow up might yield more accurate and reliable results. Also, considering the toric models of both PIOLs in further, more comprehensive studies might add to our knowledge regarding the aberrometric performance of these implants.

\section{Disclosure}

The authors report no conflicts of interest in this work.

\section{References}

1. Espandar L, Meyer JJ, Moshirfar M. Phakic intraocular lenses. Curr Opin Ophthalmol. 2008;19(4):349-356.

2. Barsam A, Allan BD. Excimer laser refractive surgery versus phakic intraocular lenses for the correction of moderate to high myopia [review]. Cochrane Database Syst Rev. 2012;1:CD007679.

3. Sanders DR. Matched population comparison of the Visian Implantable Collamer Lens and standard LASIK for myopia of -3.00 to -7.88 diopters. J Refract Surg. 2007;23(6):537-553.

4. Schallhorn S, Tanzer D, Sanders DR, Sanders ML. Randomized prospective comparison of visian toric implantable collamer lens and conventional photorefractive keratectomy for moderate to high myopic astigmatism. J Refract Surg. 2007;23(9):853-867.

5. Lovisolo CF, Reinstein DZ. Phakic intraocular lenses. Surv Ophthalmol. 2005;50(6):549-587.

6. Gimbel HV, Ziémba SL. Management of myopic astigmatism with phakic intraocular lens implantation. J Cataract Refract Surg. 2002;28(5): 883-886.

7. Güell JL, Morral M, Kook D, Kohnen T. Phakic intraocular lenses part 1: historical overview, current models, selection criteria, and surgical techniques. J Cataract Refract Surg. 2010;36(11):1976-1993.
8. Shimizu K, Kamiya K, Igarashi A, Shiratani T. Intraindividual comparison of visual performance after posterior chamber phakic intraocular lens with and without a central hole implantation for moderate to high myopia. Am J Ophthalmol. 2012;154(3):486-494. e1.

9. Shimizu K, Kamiya K, Igarashi A, Shiratani T. Early clinical outcomes of implantation of posterior chamber phakic intraocular lens with a central hole (Hole ICL) for moderate to high myopia. Br J Ophthalmol. 2012;96(3):409-412.

10. Knorz MC, Lane SS, Holland SP. Angle-supported phakic intraocular lens for correction of moderate to high myopia: Three-year interim results in international multicenter studies. J Cataract Refract Surg. 2011;37(3):469-480.

11. Toso A, Morselli S. Visual and aberrometric outcomes in eyes with an angle-supported phakic intraocular lens. J Cataract Refract Surg. 2012;38(9):1590-1594.

12. Güell JL, Vázquez M, Gris O. Adjustable refractive surgery: 6-mm Artisan lens plus laser in situ keratomileusis for the correction of high myopia. Ophthalmology. 2001;108(5):945-952.

13. Zaldivar R, Davidorf JM, Oscherow S, Ricur G, Piezzi V. Combined posterior chamber phakic intraocular lens and laser in situ keratomileusis: bioptics for extreme myopia. J Refract Surg. 1999;15(3): 299-308.

14. Leccisotti A. Bioptics: where do things stand? Curr Opin Ophthalmol. 2006;17(4):399-405.

15. Güell JL, Rodriguez-Arenas AF, Gris O, Malecaze F, Velasco F. Phacoemulsification of the crystalline lens and implantation of an intraocular lens for the correction of moderate and high myopia: four-year follow-up. J Cataract Refract Surg. 2003;29(1):34-38.

16. Colin J, Robinet A. Clear lensectomy and implantation of low-power posterior chamber intraocular lens for the correction of high myopia. Ophthalmology. 1994;101(1):107-112.

17. Alfonso JF, Baamonde B, Fernández-Vega L, Fernandes P, GonzálezMéijome JM, Montés-Micó R. Posterior chamber collagen copolymer phakic intraocular lenses to correct myopia: five-year follow-up. J Cataract Refract Surg. 2011;37(5):873-880.

18. Tahzib NG, MacRae SM, Yoon G, et al. Higher-order aberrations after implantation of iris-fixated rigid or foldable phakic intraocular lenses. $J$ Cataract Refract Surg. 2008;34(11):1913-1920.

19. Shin JY, Ahn H, Seo KY, Kim EK, Kim TI. Comparison of higher order aberrations after implantable Collamer Lens implantation and wavefront-guided LASEK in high myopia. J Refract Surg. 2012;28(2): 106-111.

20. Oliveira CM, Ferreira A, Franco S. Wavefront analysis and Zernike polynomial decomposition for evaluation of corneal optical quality. $J$ Cataract Refract Surg. 2012;38(2):343-356.

21. Porter J, Guirao A, Cox IG, Williams DR. Monochromatic aberrations of the human eye in a large population. J Opt Soc Am A Opt Image Sci Vis. 2001;18(8):1793-1803.

22. Lombardo M, Lombardo G. Wave aberration of human eyes and new descriptors of image optical quality and visual performance. J Cataract Refract Surg. 2010;36(2):313-331.

23. Holladay JT, Piers PA, Koranyi G, van der Mooren M, Norrby NE. A new intraocular lens design to reduce spherical aberration of pseudophakic eyes. J Refract Surg. 2002;18(6):683-691.

24. Bellucci R, Morselli S. Optimizing higher-order aberrations with intraocular lens technology. Curr Opin Ophthalmol. 2007;18(1):67-73.

25. Kim SW, Yang H, Yoon G, et al. Higher-order aberration changes after Implantable Collamer Lens implantation for myopia. Am JOphthalmol. 2011;151(4):653-662. e1.

26. Kohnen T, Kook D, Morral M, Güell JL. Phakic intraocular lenses: part 2: results and complications. J Cataract Refract Surg. 2010;36(12): 2168-2194.

27. Kamiya K, Igarashi A, Shimizu K, Matsumura K, Komatsu M. Visual performance after posterior chamber phakic intraocular lens implantation and wavefront-guided laser in situ keratomileusis for low to moderate myopia. Am J Ophthalmol. 2012;153(6):1178-1186. e1. 
28. Mastropasqua L, Toto L, Vecchiarino L, Doronzo E, Mastropasqua R, Di Nicola M. AcrySof cachet phakic intraocular lens in myopic patients: visual performance, wavefront error, and lens position. J Refract Surg. 2012;28(4):267-274.

29. Lane SS, Waycaster C. Correction of high myopia with a phakic intraocular lens: interim analysis of clinical and patient-reported outcomes. J Cataract Refract Surg. 2011;37(8):1426-1433.
30. Huang D, Schallhorn SC, Sugar A, et al. Phakic intraocular lens implantation for the correction of myopia: a report by the American Academy of Ophthalmology. Ophthalmology. 2009;116(11):2244-2258.
Clinical Ophthalmology

\section{Publish your work in this journal}

Clinical Ophthalmology is an international, peer-reviewed journal covering all subspecialties within ophthalmology. Key topics include: Optometry; Visual science; Pharmacology and drug therapy in eye diseases; Basic Sciences; Primary and Secondary eye care; Patient Safety and Quality of Care Improvements. This journal is indexed on

\section{Dovepress}

PubMed Central and CAS, and is the official journal of The Society of Clinical Ophthalmology (SCO). The manuscript management system is completely online and includes a very quick and fair peer-review system, which is all easy to use. Visit http://www.dovepress.com/ testimonials.php to read real quotes from published authors. 